\title{
Coat cover hair density is a symptom of primitive horse adaptation to the environment
}

\author{
Anna Stachurska', Michał Pluta' ${ }^{7}$ Mariusz Wójcik² ${ }^{2}$ Zygmunt Giżejewski ${ }^{3}$, Iwona Janczarek ${ }^{7}$, and Monika Różańska-Boczula ${ }^{4}$ \\ ${ }^{1}$ Department of Horse Breeding and Use, University of Life Sciences in Lublin, Poland \\ 2 Department of Animal Ethology and Welfare, University of Life Sciences in Lublin, Poland \\ 3 Department of Biodiversity Protection, Polish Academy of Sciences, Institute of Animal Reproduction and Food Research, Olsztyn, Poland \\ ${ }^{4}$ Department of Applied Mathematics and Computer Science, University of Life Sciences in Lublin, Poland
}

\begin{abstract}
Summary: The objective of the study was to determine whether the coat cover in Polish Konik mares is more dense in winter than in summer and whether the possible difference is effected by the system of the horses' maintenance, lactation or age. Thirty three Polish Konik horses were included: 23 mares kept in a stable and pasture/paddock, and 10 mares living on a close reserve. The study was conducted in July and December, hence summer and winter coats were analysed. The measurements were taken from single horses. Nineteen mares were examined in both seasons, whereas five mares were studied only in the summer and other nine mares only in the winter which resulted in 52 measurements in total. The mares were split into four age groups. Most of mares in both groups lactated in summer, whereas in winter only reserve mares had foals at foot. The coat hair density was determined from the horse's scapula, where an approximately $9 \mathrm{~cm}^{2}$ area was shaved to obtain hair $0.5 \mathrm{~mm}$ in length. Photographs of this area were taken and after conversion a $1 \mathrm{~mm}^{2}$ square net was put on the picture to enable counting the hair leavings. The measurement was the number of hairs in $1 \mathrm{~cm}^{2}$. Data were analyzed using three-way ANOVA with repeated measures (summer, winter), considering two factors: the system of maintenance (stable, reserve) and lactation (lactating mares, non-lactating mares). The age group factor was considered in an additional two-way ANOVA with repeated measures. Spearman's correlation, Pearson's correlations, regression and determination coefficients were determined. The results showed that the coat hair density is a symptom of primitive horses' adaptation to changing environmental conditions. The hair density is significantly higher in winter than in summer, and the density in summer and winter is correlated. The coat hair is denser in reserve mares that are subject to more severe conditions than in stable mares. In winter, the coat hair density increases with the mares' age, which may be associated with higher requirements for isolation from harsh conditions in older mares. The coat hair density is not related to the mare's lactation. These findings may be important for improving the welfare of stable horses.
\end{abstract}

Keywords: horse, coat cover, hair density, adaptation, environment

Citation: Stachurska A., Pluta M., Wóicik M., Giżejewski Z., Janczarek I., Różańska-Boczula M. (2018) Coat cover hair density is a symptom of primitive horse adaptation to the environment. Pferdeheilkunde 34, 550-556; DOI 10.21836/PEM20180606

Correspondence: Prof. Anna Stachurska PhD, Department of Horse Breeding and Use, University of Life Sciences in Lublin, Akademicka 13, 20-950 Lublin, Poland; anna.stachurska@up.lublin.pl

\section{Introduction}

Many characteristics of the hair coat cover may illustrate adaptation of domesticated horses (Equus caballus) to their environments. Such changes are most distinct in primitive breeds that are more closely related to wild horses than specialized breeds after centuries of breeding. Lightening of the blue-dun color in primitive Polish Konik horses in winter is probably a protective feature which once acted in wild ancestors as a camouflage to hide from predators in the snow (Stachurska et al. 2004). Darker horses are less noticeable in the summer. Extinct Tarpans (Equus ferus) were blue dun and, as wild horses, did not have white markings probably for better camouflage (Jezierski and Jaworski 2008).

Shedding of winter hair coat in any horse is affected by day length, and the process may be stimulated by extended photoperiod treatment (Kooistra and Ginther 1975). The shedding results from prolactin action being increased as a consequence of the extended photoperiod (Thomson and DePew 1997, Thomson et al. 1997, Kunii et al. 2015). In primitive horses living on a reserve, shedding of winter coat hair shows a strong association with air temperature (Stachurska et al. 2015). Winter coat cover remains in the spring for a longer time in the shoulders, back and loins than in the chest and belly, whereas the hindquarters shed the first. This phe- nomenon is probably associated with the need of better protection against precipitation of most sensitive organs in thorax and loins.

Coat cover hairs in primitive horses in winter are much longer than in summer, which seems to be an evident factor providing better isolation from cold, wind and high precipitation in the winter (Stachurska et al. 2006). In addition, the winter cover consists of two layers: outercoat and undercoat. Unlike other mammals, e.g. sheep (Ovis aries), the underhairs usually have an inner medulla, but the diameter of the medulla is smaller than in the outerhairs. The underhairs form a distinctly shorter layer than the outerhairs.

Studies on Przewalski horses (Equus przewalskii) (Yasinetskaja 1999) and Polish Konik horses (Stachurska et al. 2007) showed that the coat cover hairs are thinner in winter than in summer. This phenomenon may be due to hormone changes induced by day length increase in the spring, causing hair follicles to enter catagen (regressive phase of the hair cycle) and telogen (dormancy) (Nixon et al. 2002, Legrand et al. 2014). On the other hand, in the summer, nutrition is richer and more differentiated than in winter, which can increase the horse hair thickness. Differences in hair thickness between stabled horses and those living on a reserve may be caused by both the shortened day length under stable conditions and 
the diet content (Stachurska et al. 2007). The richer diet of horses living on a reserve in the summer is probably a reason for their thicker hairs than in stabled horses and, conversely, the poor diet on reserves in the winter causes hairs to be relatively thinner than in the stabled horses.

It seems that to provide good protection from harsh conditions and due to winter hairs being thinner than summer hairs, the horse's skin produces more coat hairs in the winter. The objective of the study was to determine whether the coat cover in Polish Konik mares is denser in the winter than in the summer and whether the possible difference is effected by the system of the horses' maintenance, lactation or age.

\section{Materials and Methods}

Horses, horse maintenance and study schedule

In the study, 33 Polish Konik mares were included. Polish Konik horses are an indigenous breed closely related to the wild Tarpan, and preserved as animal genetic resources (Blackburn 2004, Komosa et al. 2013). They are primitive, small, mild horses with blue-dun coat color without white markings (Jezierski and Jaworski 2008). The horses studied were living in Roztocze National Park in Zwierzyniec. One group of 23 mares was born in a stable and kept there with daily access to a pasture/paddock (stable horses) and another group of 10 mares was born and lived on a reserve, a few kilometers from the stable (reserve horses). The park is located in southeast Poland $\left(50^{\circ} 37^{\prime} 00^{\prime \prime} \mathrm{N} 22^{\circ} 58^{\prime} 00^{\prime \prime} \mathrm{E}\right)$ where the climate is temperate and four seasons occur, of which winter and summer differ the most (Trenberth 1983). The mean temperature is below $0^{\circ} \mathrm{C}$ in winter (December 8 to March 9) and over $15^{\circ} \mathrm{C}$ in summer (June 8 to September 8 ).

The stable horses were housed and fed in suitably regulated conditions. They were free to move and interact inside the stable, in a pasture in summer and paddock in winter. They were released outside the stable for 6-7 hours a day. The size of the stable, pasture and paddock conformed to the rules of keeping horses. The stable was bedded with straw. There was mainly grass of multiple species, some legumes and herbs growing in the pasture. The stable horses were fed oats and hay in amounts dependent on feeding requirements connected with use and richness of the pasture. Their coat cover was not cleaned (brushed) and only their hooves were trimmed twice a year.

The reserve is an enclosed 94 ha area: mainly forest, some meadows, a stream and ponds, and no shelters. Human interference in the horse herd consists of providing hay during heavy snow cover. In addition, the reserve horses are sometimes goaded to a paddock and caught to trim hooves, select yearlings or change a sire. Hence, the horses are slightly accustomed to people.

The study was conducted in the middle of July and the middle of December. The horses were from over 1 to 23 years old. Their age during the study was determined in months and the data were split into four age groups: below 37, 37-72, 73-108 and over 108 months $(1-3,4-6,7-9$ and over 10 years old, respectively). In July, most of the mares were in the first trimester of pregnancy. In December, they ended the second trimester. Most of the mares also had foals at foot: in July in both groups and in December only in the reserve group. Since the pregnancy in the first two trimesters does not considerably affect the dam's requirements (Davis Morel 2008), only lactation was taken into account. Winter hair in Polish Konik horses living on this reserve grows longer mainly in September and is shed in April and the first half of May (Stachurska et al. 2015). Thus, we analyzed summer and winter coat cover. The measurements were taken from single horses. Nineteen mares were examined in both seasons, whereas five mares were studied only in the summer and other nine mares only in the winter which resulted in 52 measurements in total. Numbers of measurements in groups of mares considered in the analysis (52 in total) are shown in Table 1.

\section{Collection and analysis of the material}

The density of the coat cover was determined from the left scapula, in the middle of its length. This even surface was chosen to obtain precise photographs. It was not possible to delineate a distinct area of a definite surface in the coat cover or to count long hairs in it, hence the hairs were cut and their leavings were counted. An area of approximately $3 \times 3 \mathrm{~cm}$ was shaved with Philips clippers (HC5440) to obtain hair approximately $0.5 \mathrm{~mm}$ in length. In winter cover, the hair was so long that it had to be first cut with curved scissors. Photographs of this area were taken using a Canon EOS M camera with 18 megapixels image sensor equipped with Macro lens Tokina AT-X M Pro D $100 \mathrm{~mm}$ f/2.8 with maximum magnification of $1 \times$ and macro ring flash Soligor AR-40. The maximum magnification of $1 \times$ at minimum focus distance of $30 \mathrm{~cm}\left(11.81^{\prime \prime}\right)$ from the horse's skin was always used. Pictures were taken in Canon's RAW/CR2 format, then the RAW was converted using Digital Photo Professional v. 4.6.30 software to TIFF format. Next step was to draw a grid of squares $232 \times 232$ pixels using filters in GIMP 2.8.10 (GNU Image Manipulation Program), the free and open source image editor. The image sensor size was $22.3 \mathrm{~mm} \times 14.9 \mathrm{~mm}$, and the maximum picture resolution was $5184 \times 3456$, hence the square of $232 \times 232$ pixels was $1 \mathrm{~mm}^{2}$ in $1: 1$ (life size). The coat hair density was determined by the number of hairs in 100 areas of $1 \mathrm{~mm}^{2}$ (Figure 1). The outerhairs and underhairs were not possible to distinguish (Stachurska et al. 2006).

\begin{tabular}{|c|c|c|c|c|c|c|c|c|}
\hline \multirow[b]{2}{*}{ Season } & \multicolumn{2}{|c|}{ System of maintenance } & \multicolumn{2}{|c|}{ Lactation } & \multicolumn{4}{|c|}{ Age group (months) } \\
\hline & stable & reserve & non-lactating & lactating & below 37 & $37-72$ & $73-108$ & over 108 \\
\hline Summer & 17 & 7 & 9 & 15 & 4 & 7 & 6 & 7 \\
\hline Winter & 19 & 9 & 11 & 17 & 5 & 7 & 7 & 9 \\
\hline Total & 36 & 16 & 20 & 32 & 9 & 14 & 13 & 16 \\
\hline
\end{tabular}


Thus, the measurement was a sum of the outerhairs and underhairs in $1 \mathrm{~cm}^{2}$.

\section{Statistical analysis}

The statistical analysis was performed using the Statistica 13.1 package (StatSoft 2018). A coefficient of variation was calculated to determine whether the material was strongly dispersed. The data were analyzed using a three-way ANOVA (GLM) with repeated measures (main analysis). The factor of repeated measures was the season of the year (summer, winter). The independent variables were the system of maintenance (stable, reserve) and lactation (lactating mares, nonlactating mares), whereas the dependent variable was the coat hair density in mares. The age group factor could not be included in the main analysis because the material was too dispersed, hence a two-way ANOVA (GLM) with repeated measures was also performed.

The following research hypotheses were verified: lack of repeated measure effect (the season of the year); lack of group effect (within the system of maintenance, lactation and age group) as well as a lack of interaction effect. To verify these hypotheses, the F-Snedecor test was used, assuming a significance level of $\alpha=0.05$. Because the Shapiro-Wilk test rejected the normality of the coat hair density distribution in winter $(p=0.026)$, the data were transformed with decimal logarithm before the ANOVA was conducted. In the case of each factor, Levene's test showed the homogeneity of variances $(p>0.05)$.

A Spearman's rank correlation coefficient was determined between the summer and winter coat hair density, and the mare's age (in months). The dependence between the hair coat density in summer and winter was determined using a linear Pearson's correlation coefficient. This relationship was also analyzed with a regression model and a regression coefficient verified by F-Snedecor test and Student's t-test, respectively. The determination coefficient was calculated to show the variance percentage of the winter coat hair density explained by the regressive dependence of the summer coat hair density.

\section{Results}

The coefficients of variation below $20 \%$ indicated a uniformity of the feature studied, i.e. a low dispersion of the hair coat density in relation to the means in particular groups divided with regard to the system of maintenance, lactation and age group (Table 2).

The results of the main ANOVA considering the seasonal repeated measurements are presented in Table 3. The season of the year $(p=0.0004)$ and system of maintenance $(p=0.0024)$ significantly affected the coat hair density in mares. Instead, the lactation was a non-significant factor $(p=0.2113)$. The interaction effects of both second and third order were also non-significant ( $p>0.05)$. Moreover, the age group factor in the second ANOVA was also non-significant $(p=0.5977)$.

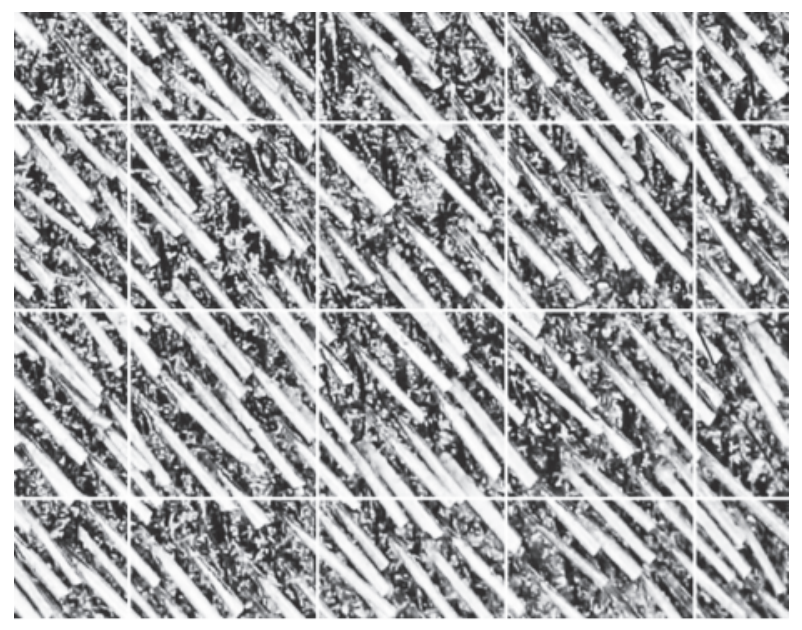

Fig. 1 Skin with cut hairs divided with $1 \mathrm{~mm}^{2}$ square net.

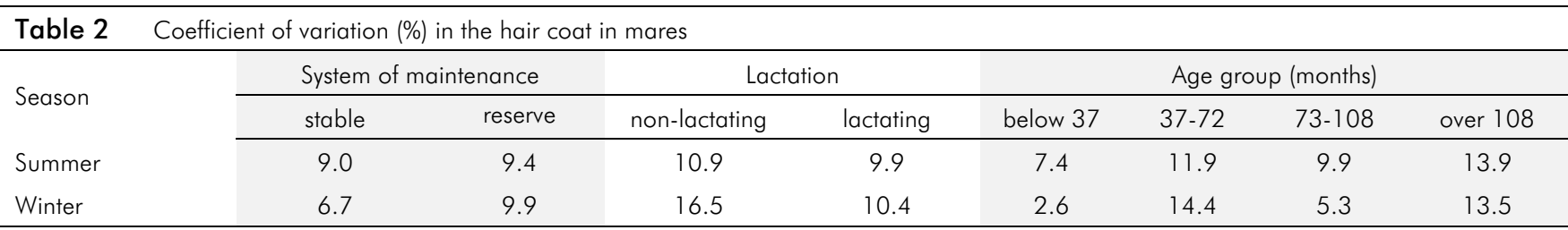

Table 3 Significance of effects considered in the main analysis

\begin{tabular}{|c|c|c|c|}
\hline Sources of variation & $d f$ & $\mathrm{~F}$ & $p$ \\
\hline Season & 1 & $21.663^{* *}$ & 0.0004 \\
\hline System of maintenance & 1 & $13.645^{* *}$ & 0.0024 \\
\hline Lactation & 1 & 1.716 & 0.2113 \\
\hline Season ${ }^{*}$ system of maintenance & 1 & 0.658 & 0.4308 \\
\hline Season * lactation & 1 & 2.234 & 0.1572 \\
\hline System of maintenance ${ }^{*}$ lactation & 1 & 1.441 & 0.2499 \\
\hline Season * lactation ${ }^{*}$ system of maintenance & 1 & 0.089 & 0.7694 \\
\hline
\end{tabular}

$\mathrm{df}$ - degrees of freedom; F - value of F-Snedecor test; $\mathrm{p}$ - probability value; ${ }^{* *}$ factor significant at $\mathrm{p}<0.01$ 


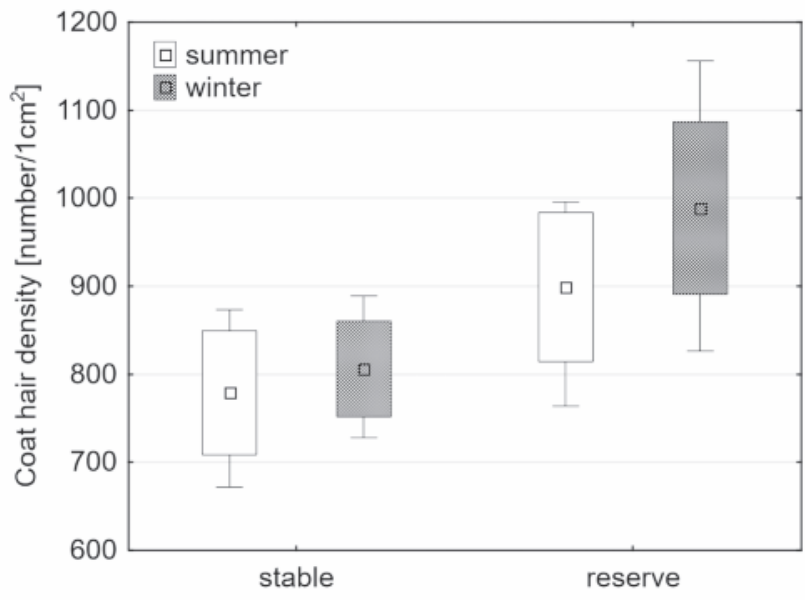

Fig. 2 Coat hair density in mares with regard to the season of the year and system of maintenance (a square shows a mean, a box corresponds to the range of the mean \pm standard deviation and "whiskers" above and below the box show the locations of the minimum and maximum).

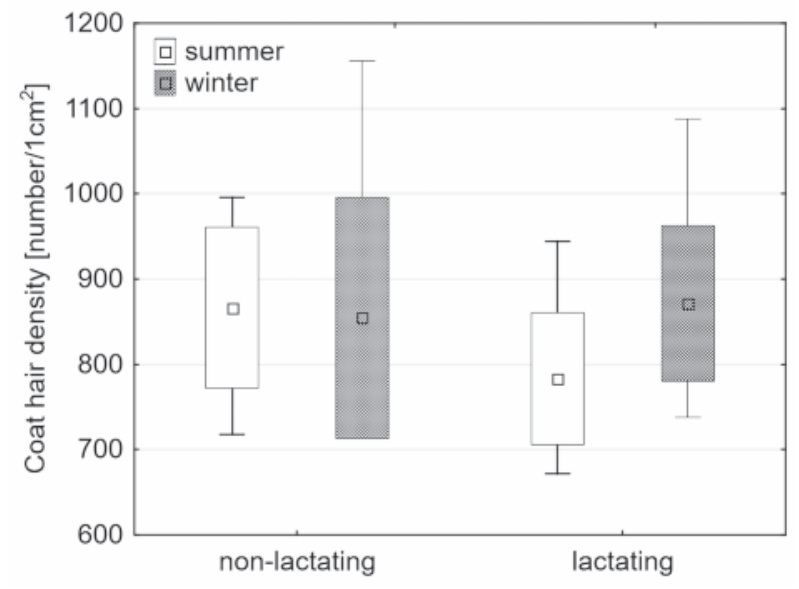

Fig. 3 Coat hair density in mares with regard to the season of the year and lactation (a square shows a mean, a box corresponds to the range of the mean \pm standard deviation and "whiskers" above and below the box show the locations of the minimum and maximum).

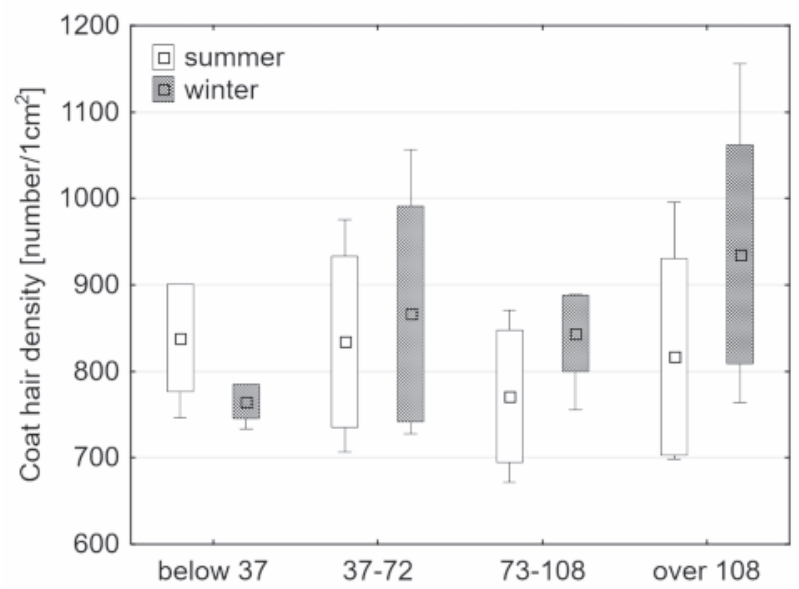

Fig. 4 Coat hair density in mares with regard to the season of the year and age group - months (a square shows a mean, a box corresponds to the range of the mean \pm standard deviation and "whiskers" above and below the box show the locations of the minimum and maximum).
The coat hair density with regard to the season of the year and system of maintenance is presented in Figure 2. A significantly higher density was found in the winter (865.0 \pm 111.0 ) than in the summer $(814.4 \pm 91.7)$ and in the reserve mares $(949.6 \pm 100.5)$ compared to the stable mares (793.6 \pm 62.9$)$, although as mentioned, the interaction between those effects was non-significant. Similarly, the lactation and the interaction between the lactation and the season of the year were non-significant (Figure 3). However, a tendency of a higher coat hair density in the winter than in summer was visible in the lactating mares.

A growing tendency of the coat hair density in the winter was also seen in successive age groups, although the age group factor was non-significant (Figure 4). This finding corresponds to the positive and significant Spearman's rank correlation coefficient $(r=0.4880, p=0.001)$, showing the relationship between the winter coat hair density in the mares and their age (in months). In the summer, the correlation was negative but non-significant ( $r=-0.2480, p=0.809)$.

The linear Pearson's correlation coefficient showed a relationship between coat hair density in the mares and the two seasons of the year $(r=0.9126, p<0.0001)$. This dependence between the coat hair density in the winter $\left(d_{w}\right)$ and in the summer $\left(d_{s}\right)$ was also shown by the significant regression model $(p<0.0001)$ and regression coefficient $(p<0.0001)$ :

$$
d_{w}=1.003 \times d_{s}+64.04
$$

The determination coefficient showed that the variance percentage of the winter coat hair density explained by the regressive dependence of the summer coat hair density was high $\left(R^{2}=0.83\right)$.

\section{Discussion}

To determine the ability of horses to adapt to the environment, we chose animals as similar as possible to wild horses living centuries ago. Since domestication, horses have usually been maintained in stable conditions, hence they could have lost their resistance to illnesses and become more sensitive to harsh environmental conditions. Nowadays, Polish Konik horses seem to be the best animal model to investigate phenomena typical for the species. Firstly, the Polish Konik is a tough primitive breed with low environmental requirements. In such horses, the mechanism of adaptation to the environment is more distinct than in warmblood or coldblood horses maintained under stable conditions. Secondly, some Polish Koniks live on reserves, which resembles living in wild. Because they almost lack human interference, these horses experience the most severe conditions, involving the strongest response of the body, especially in the winter. Thirdly, some of the Polish Koniks studied are maintained under the usual stable system, whereas others live on the reserve in proximity of the stable, which enables comparative research.

It should be noted that, for the study, we elaborated an accurate simple method of measuring the coat hair density. Previously, the coat cover was assessed "by eye", according to a scale (Kunii et al. 2015). For studies on hair coat characteristics in cattle (Bos taurus), hair samples were taken with pliers, 
modified to pull hair from a small known area of animal skin (Udo 1978). However, it was mentioned that such samples might include not all short hairs from this area. A method of weighting hair samples was regarded as a misleading measure because it was determined by three simultaneous parameters: number of hairs, their length and diameter. The reported studies did not specify methods of overcoming the difficulty in exact measuring the skin area covered with hairs.

The results show that the coat hair density in Polish Konik mares is significantly higher in the winter than in the summer. Thus, the hypothesis for the lack of season effect was rejected. The changes in coat density may be regarded as seasonal acclimatization. The high Pearson's correlation means that when a hair coat in a mare is denser in summer, it is also denser in winter, relative to the other horses. This phenomenon shows there are individual differences between horses, but the mechanism of a denser cover in winter than in summer is the same in all horses. The regression model and coefficient confirm the dependence and show an increase of the coat hair density in the winter compared to the summer. A study on heifers in the Netherlands revealed that summer hair coat was less dense than winter hair coat (Udo 1978).

It was expected that many factors may affect the coat hair density besides the season of the year and the mentioned individual adaptation abilities. One of these, and a considerable effect, is the system of maintenance: the coat hair density is higher in reserve mares than in stable mares. This fact is easy to explain because the environmental conditions on a reserve are far more severe than in a stable, hence they affect the adaptation mechanism more strongly. Earlier studies on coat hair color, length and width showed that in each case, seasonal differences were more pronounced under reserve conditions (Stachurska et al. 2004, 2006, 2007).

There was no effect of age group. However, both the analysis of variance and Spearman's coefficient showed that, in the winter, the coat hair density increased with the mares' age. This fact may be associated with higher requirements for an isolation from harsh environmental conditions in older mares. There was no effect of lactation on coat hair density. In July, both groups of mares had already experienced peak lactation, when mare's nutritional demands are increased (Santos and Silvestre 2008). On a reserve, suckling foals are naturally weaned at 9-10 months of age or are at foot until the time of next parturition; however, in December they consumed solid food with minimal reliance on milk. It seems that the summer or winter coat hair density does not considerably change during a season (summer/winter), hence even in the peak lactation a similar result could be expected. Interestingly, no effect of pregnancy and lactation upon coat score was found in cows (Turner and Schleger 1960).

The determination coefficient indicates that $83 \%$ of the coat hair density variance in the winter is explained by the regressive dependence of the coat hair density in the summer. Only the remaining $17 \%$ is an effect of other factors, possibly the system of maintenance. This finding strongly indicates the seasonal influence on the coat hair density, which, on the other hand, shows that the density is a symptom of adaptation to the environment. The dense winter coat cover better isolates the body from the environment, particularly in the situation of thinner winter hairs. This phenomenon explains the necessity of coat cover shedding in the spring.

These findings may be extrapolated to other horse breeds. Understanding the mechanisms of coat cover changes that originally enabled horses to live in the wild may help improve the welfare of stable horses. This does not mean that natural conditions are suitable for contemporary horses, but furthers better understanding of the functioning of the species.

\section{Conclusion}

In conclusion, the coat cover hair density is a symptom of primitive horses' adaptation to changing environmental conditions. The coat hair density in Polish Konik mares is significantly higher in the winter than in the summer, and the density in summer and winter is correlated. The coat is also denser in reserve mares that are subject to more severe conditions than in stable mares. In winter, the coat hair density increases with the mares' age, which may be associated with higher requirements for isolation from harsh conditions in older mares. The coat hair density is not related to mare's lactation. Understanding the natural mechanisms of coat cover changes may be important for improving the welfare of stable horses.

\section{Acknowledgements}

We acknowledge Roztocze National Park authorities for making available studying the horses.

\section{Funding statement}

This study was supported by Faculty of Biology, Animal Sciences and Bioeconomy, University of Life Sciences in Lublin.

\section{Conflict of interest}

The authors declare that they have no conflict of interest.

\section{Animal welfare statement}

The study did not need an approval of Ethical Committee for Animal Experiments since it consisted of routinely conducted procedures in usual domesticated horse management, which did not involve any pain or suffering to horses (www.dziennikustaw.gov.pl/du/2015/266/1). The authors followed standard institutional guidelines concerning human contact with stabled horses and horses living on a reserve.

\section{References}

Bartošová J., Komárková M., Dubcová J., Bartoš L., Pluháček J. (2011) Concurrent lactation and pregnancy: pregnant domestic horse mares do not increase mother-offspring conflict during intensive lactation. PLoS One 6:e22068; DOI 10.1371/journal. pone.0022068

Blackburn H. D. (2004) Development of national animal genetic resource programs. Reprod. Fert. Develop. 16, 27-32; DOI $10.10371 / R D 03075$ 
Davies Morel M. C. G. (2008) Equine reproductive physiology, breeding and stud management. 3rd ed., CABI Publishing, Wallingford, pp. 178-183

Jezierski T., Jaworski Z. (2008) Das Polnische Konik. 1st ed., Westarp Wissenschaften-Verlagsgesellschaft mbH, Hohenwarsleben, p. 95

Komosa M., Frackowiak H., Purzyc H., Woinowska M., Gramacki A., Gramacki J. (2013) Differences in exterior conformation between primitive, Half-bred, and Thoroughbred horses: Anatomic-breeding approach. J. Anim. Sci. 91, 1660-1668; DOI 10.2527/jas. 2012-5367

Kooistra L. H., Ginther O. J. (1975) Effect of photoperiod on reproductive activity and hair in mares. Am. J. Vet. Res. 36, 1413-1419

Kunii H., Nambo Y., Okano A., Matsui A., Ishimaru M., Asai Y., Sato F., Fuiii K., Nagaoka K., Watanabe G., Taya K. (2015) Effects of an extended photoperiod on gonadal function and condition of hair coats in Thoroughbred colts and fillies. J. Equine Sci. 26, 57 66; DOI 10.1294/jes.26.57

Legrand R., Tiret L., Abitbol M. (2014) Two recessive mutations in FGF5 are associated with long-hair phenotype in donkeys. Genet. Sel. Evol. 46, 65-71; DOI 10.1186/s12711-014-0065-5

Nixon A. J., Ford C. A., Wildermoth J. E., Craven A. J., Ashby M. G., Pearson A. J. (2002) Regulation of prolactin receptor expression in ovine skin in relation to circulating prolactin and wool follicle growth status. J. Endocrinol. 172, 605-614

Santos A. S., Silvestre A. M. (2008) A study of Lusitano mare lactation curve with Wood's model. J. Dairy Sci. 91, 760-766; DOI 10.3168/jds.2007-0057

Stachurska A., Klimorowska A., Pięta M., Jaworski Z. (2007) Coat hair thickness in Polish Konik horses. Ann. Anim. Sci., Suppl. 1, 81-85
Stachurska A., Pięta M., Jaworski Z., Ussing A. P., Bruśniak A., Florek M. (2004) Colour variation in blue dun Polish Konik and Biłgoraj horses. Livest. Prod. Sci. 90, 201-209

Stachurska A., Pięta M., Jaworski Z., Ussing A. P., Pluta M. (2006) Factors that influence coat hair length in primitive horses (Equus caballus). J. Food Agric. Environ. 4, 215-219

Stachurska A., Robovský J., Bocian K., Janczarek I. (2015) Changes of coat cover in primitive horses living on a reserve. J. Anim. Sci. 93, 1411-1417; DOI 10.1016/i.livprodsci.2004.04.002; 10. 25/jas.2014-8668

StatSoft Inc. (2013) Electronic statistics textbook. Tulsa: StatSoft http://www.statsoft.com/textbook/. Accessed February 2018

Thompson D. L. Jr, DePew C. L. (1997) Prolactin, gonadotropin, and hair shedding responses to daily sulpiride administration in geldings in winter. J. Anim. Sci. 75, 1087-1091

Thompson D. L. Jr, Hoffman R., DePew C. L. (1997) Prolactin administration to seasonally anestrous mares: reproductive, metabolic, and hair-shedding responses. J. Anim. Sci. 75, 1092-1099

Trenberth K. E. (1983) What are the seasons? B. Am. Meteorol. Soc. 64, 1276-1282

Turner H.. G., Schleger A. V. (1960) The significance of coat type in cattle. Aust. J. Agric. Res. 11, 645-663

Udo H. M. J. (1978) Hair coat characteristics in Friesian heifers in The Netherlands and Kenya. H. Veenman \& Zonen BV, Wageningen, pp. 50, 63-68

www.dziennikustaw.gov.pl/du/2015/266/1 (in Polish). Accessed March 2016

Yasinetskaja N. I. (1999) Seasonal variability of hair coat in the Przewalski Horse. Vestn. Zoologia, Suppl. 11, 234-240 